\title{
Dying uterus, uterine artery ligation-a curse or a blessing? a rare case report
}

\author{
Preeti Frank Lewis, Mridula Raghav*, Roopali Sanjay Sehgal
}

Department of obstetrics and gynaecology, Sir J. J. Group of Hospitals, Mumbai, Maharashtra, India

Received: 09 August 2021

Accepted: 06 September 2021

\section{*Correspondence:}

Dr. Mridula Raghav,

E-mail: drmridularaghav@ @otmai

Copyright: ( ) the author(s), publisher and licensee Medip Academy. This is an open-access article distributed under the terms of the Creative Commons Attribution Non-Commercial License, which permits unrestricted non-commercial use, distribution, and reproduction in any medium, provided the original work is properly cited.

\begin{abstract}
Uterine necrosis is a rare life-threatening condition reported in few case reports associated with uterine artery embolization for uterine fibroids or postpartum hemorrhage. We report a case of hemorrhagic uterine necrosis in a 22year-old primipara day 4 post emergency caesarean section who presented with breathlessness, abdominal distension and severe anaemia. Patient underwent emergency exploratory laparotomy 2 hours after the caesarean section with intraoperative findings suggestive of rectus muscle hematoma, bilateral uterine artery ligation was done for atonic PPH. On clinical examination uterus was corresponding to 28-30 weeks gestation size with guarding and tenderness. Ultrasonography revealed bulky uterus. CT abdomen with pelvis with contrast was done with findings suggestive of hemorrhagic ischaemic myometrial necrosis. An emergency exploratory laparotomy was performed with intraoperative findings of uterus size of 30 weeks gestation with diffuse congestion, gangrene of bilateral tubes and ovaries. Obstetric hysterectomy with bilateral salpingo-oovarectomy was done. Patient was discharged on postoperative day 9 . High index of clinical suspension, prompt CT imaging and exploratory laparotomy on time proved life-saving.
\end{abstract}

Keywords: Postpartum uterine necrosis, Uterine artery ligation, Obstetric hysterectomy, Uterine gangrene, Myometrial necrosis

\section{INTRODUCTION}

Uterine necrosis is a rare life-threatening condition reported only in few case reports and series. ${ }^{1}$ It can be associated with uterine artery embolization for uterine fibroids or postpartum hemorrhage and caesarean delivery. Regardless of aetiology, prompt treatment with antibiotics and hysterectomy is the main stay to prevent septicemia. As uterine necrosis is rare, there are few descriptions of the associated imaging findings. Imaging plays an important role in diagnosis. Ultrasound imaging is the first line as it shows a large uterus with a redesigned wall and a heterogeneous image is associated with the presence of air in the uterus. ${ }^{2}$ The use of CT is also often useful, as in our case, it revealed uterine necrosis with the presence of gas bubbles in the myometrium.

\section{CASE REPORT}

22 years old, P1L1 day 4 post emergency caesarean section presented with complaints of abdominal distension for 4 days, acute in onset, decreased urine output and breathlessness for 4 days. Emergency caesarean section was done in vivo of premature rupture of membranes with oligohydramnios. Patient developed syncopal attack post operatively with bleeding per vaginum and was shifted for emergency exploratory laparotomy with intraoperative findings of evacuation of 150-200 cc of rectus muscle hematoma. Bilateral uterine artery ligation was also performed for atonic PPH. Patient was transfused with 4 pints of blood and 3 pints of fresh frozen plasma and referred to our institute for further management. 
On general examination patient pulse rate was 120 beats/min, pallor was present, per abdomen examination revealed guarding and diffuse tenderness, abdominal girth of $78 \mathrm{~cm}$ and symphysio-fundal height of $28 \mathrm{cms}$, uterus was corresponding to 30 weeks gestation with suspicion of uterine sub involution, urine output was around $50 \mathrm{cc}$. On investigating further haemoglobin was $6 \mathrm{~g} \%$, total leucocyte counts 16,300 , platelets 1.3 lacs, ECG suggestive of sinus tachycardia, ultrasonography of abdomen and pelvis showed bulky uterus. Patient was started on higher antibiotics, vitals monitoring and due to high clinical suspicion of uterine sub-involution a CT abdomen with pelvis with contrast was planned. CT was suggestive of enlarged uterus reaching up to D12-L1 vertebral level with hemorrhagic changes and air foci within suggestive of hemorrhagic ischaemic myometrial necrosis (Figure 1).

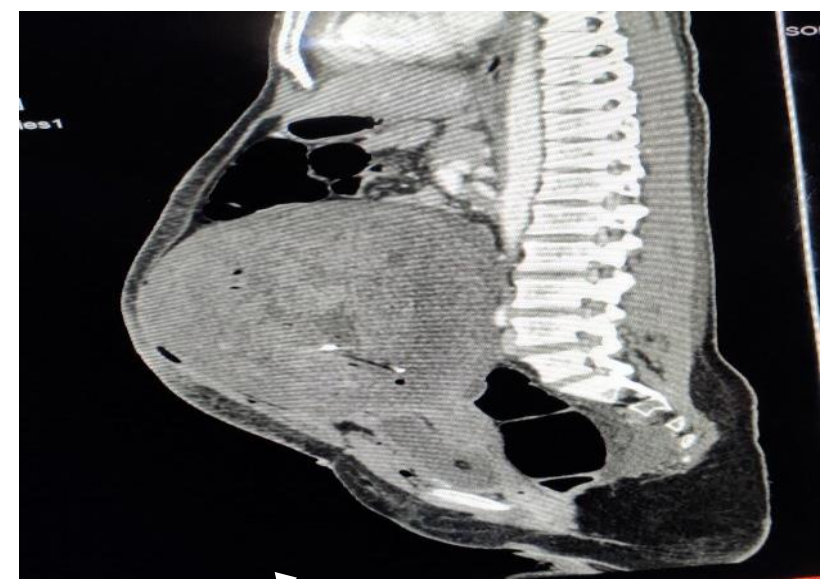

Figure 1: Sagittal CT image of thickened non enhancing myometrium with hemorrhagic changes and air foci within (encircled).

Patient was transfused two pints of PCV with post transfusion hemoglobin as $8.6 \mathrm{~g} \%$. Prothrombin time was 22 with INR 1.577, D-dimer-6335 hence fresh frozen plasmas were transfused as well. Patient developed two fever spikes with raising total leucocyte count $-25,500$ suspected of early onset sepsis hence decision for emergency exploratory laparotomy with SOS obstetric hysterectomy was taken. Emergency exploratory laparotomy with obstetric hysterectomy with bilateral salpingo-oovarectomy with bilateral internal iliac artery ligation under general anaesthesia was performed with intraoperative findings suggestive of-uterus size corresponding to 30 weeks gestation with massive uterine congestion? hemorrhagic necrosis, bilateral tubes and ovaries blackened completely suggestive of gangrene, perfusion test negative for blood supply (Figure 3). 1 pint blood and 4 fresh frozen plasma were transfused intraoperatively. Post-operatively patient was shifted to critical care unit. Post-op investigations-Hemoglobin 10 $\mathrm{g} \%$, total leucocyte counts 20,000 , rest within normal limits.

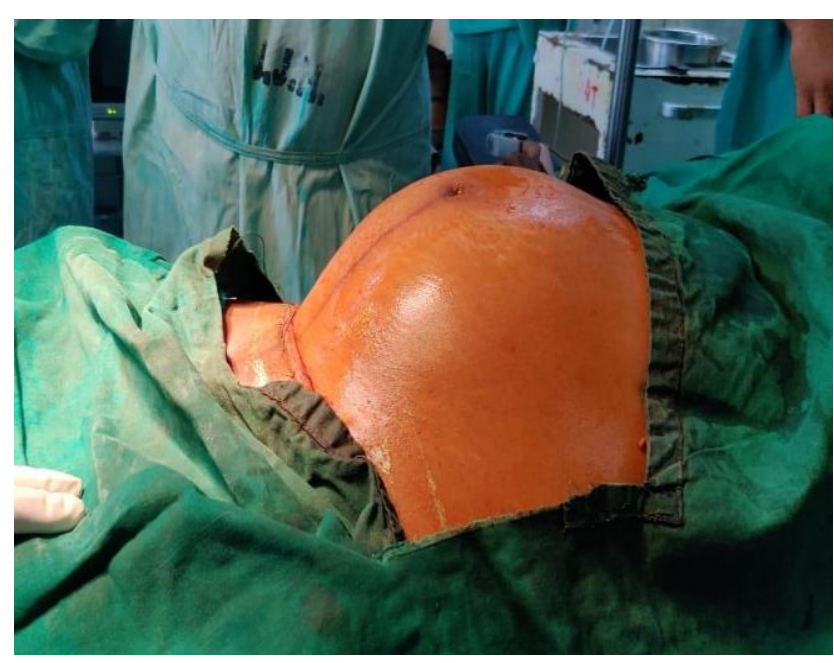

Figure 2: Lateral view of abdomen.

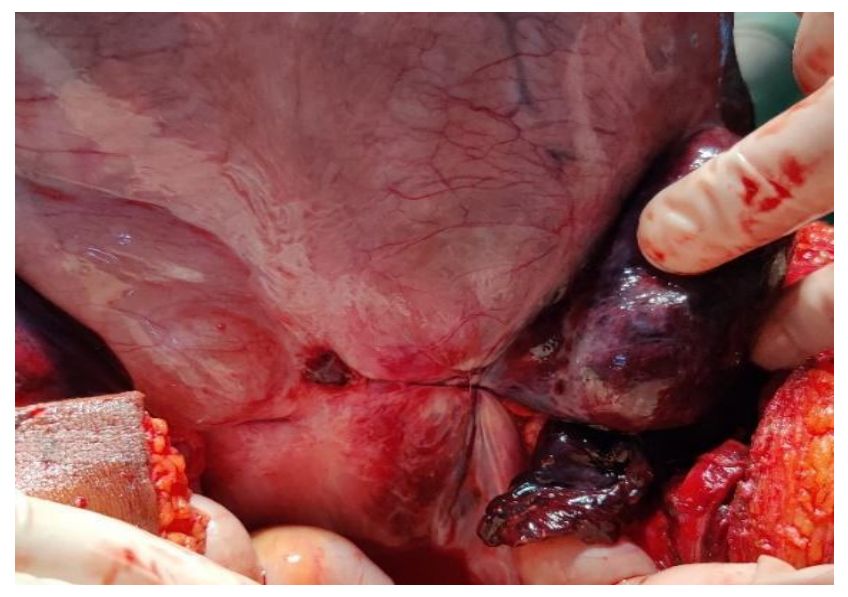

Figure 3: Uterus corresponding to 30 weeks gestation size of diffuse congestion. Bilateral tubes and ovaries gangrenous.

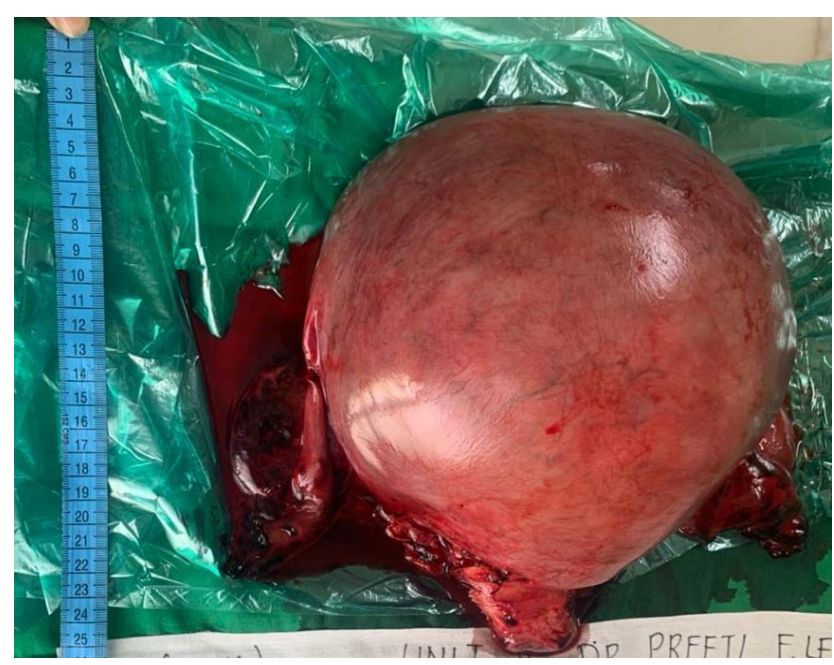

Figure 4: Uterocervical length of about $26 \mathrm{~cm}$.

Post-operative ultrasonography of abdomen with pelvis was within normal limits. Check dress was done on day 5 , 
suture line was healthy. Patient was discharged on day 9 post-op after suture removal.

\section{DISCUSSION}

Conventionally, the first-line treatment options for $\mathrm{PPH}$ include conservative management with uterotonic drugs (oxytocin or prostaglandins), while second-line therapy includes uterine packing, external compression with uterine sutures, selective devascularisation by ligation, or embolization of the uterine artery. ${ }^{3-7}$

There are many surgical techniques for the management of postpartum bleeding. Systemic pelvic devascularization, compression sutures- B-lynch, Cho's, Hayman's (main aim being compression of placental bed as the source of bleeding). If not performed by expert hands, can cut- off the blood supply of uterus and both tubes and ovaries as seen in our case. As a result, patient can land up into uterine necrosis which is a life-threatening condition if not diagnosed or treated promptly. Uterine necrosis can present clinically as sub-involuted tender uterus accompanied by signs and symptoms of septicemia. Hysterectomy under coverage of higher antibiotics is the treatment of choice for hemorrhagic ischaemic myometrial necrosis.

\section{CONCLUSION}

If not diagnosed on time uterine necrosis can be life threatening, knowledge of ligation technique for surgical management of postpartum hemorrhage is necessary. High index of clinical suspicion with CT imaging can prove lifesaving as in our case.

Funding: No funding sources Conflict of interest: None declared

Ethical approval: The study was approved by the Institutional Ethics Committee

\section{REFERENCES}

1. Couvelaire A. Deux nouvelles observations d'apoplexie utero-placentaire (hemorrhagies retroplacentaires avec infiltration sanguine de la pavoi musculaire de l'uterus). Ann Gynecol Obstet. 1912;9(1):486.

2. Giusti S, Fanti F, Cecchi E, Capriello P, Malacarne E, Marmorato $\mathrm{M}$ et al. Hemorrhagic uterine necrosis after surgical vessel ligation and B-Lynch suture in persistent postcesarean uterine atony: case report and review of literature. Int J Reprod Contracept Obstet Gynecol. 2016;5:4046-51.

3. Condous GS, Arulkumaran S. Medical and conservative surgical management of postpartum hemorrhage. J Obstet Gynaecol Can. 2003;25:931-6.

4. B-Lynch C, Coker A, Lawal AH, Abu J, Cowen MJ. The B-Lynch surgical technique for the control of massive postpartum haemorrhage: an alternative to hysterectomy? Five cases reported. Br J Obstet Gynaecol. 1997;104:372-5.

5. Hayman RG, Arulkumaran S, Steer PJ. Uterine compression sutures: surgical management of postpartum hemorrhage. Obstet Gynecol. 2002;99:502-6.

6. Doumouchtsis SK, Papageorghiou AT, Arulkumaran S. Systematic review of conservative management of postpartum hemorrhage: what to do when medical treatment fails. Obstet Gynecol Surv. 2007;62:540-7.

7. Royal College of Obstetricians and Gynaecologists. RCOG Green-top guideline. Prevention and management of postpartum haemorrhage. 2009;52.

Cite this article as: Lewis PF, Raghav M, Sehgal RS. Dying uterus, uterine artery ligation-a curse or a blessing? a rare case report. Int J Reprod Contracept Obstet Gynecol 2021;10:4017-9. 